\title{
Long term results (15-30 years) of surgical repair of aortic coarctation
}

\author{
P PRESBITERO, D DEMARIE, M VILLANI, E ACTIS PERINETTO, G RIVA, \\ F ORZAN, M BOBBIO, M MOREA, A BRUSCA
}

From the Istituto di Medicina e Chirurgia Cardiovascolare, Università di Torino, Turin, Italy

SUMMARY The late outcome in 226 patients who survived surgical repair of aortic coarctation was assessed 15-30 years after operation. Twenty six patients died during the follow up mainly from causes related to surgical repair or to associated cardiovascular anomalies. The survival rates of patients operated on between the ages of four and 20 years are $97 \%, 97 \%, 92 \%$ at 10,20 , and 30 years after operation. For patients operated on after the age of 20 the corresponding rates are $93 \%, 85 \%$, and $68 \%$. This difference is statistically significant from the fifteenth year of follow up onwards. The survival of patients operated on before the age of 20 is not significantly different from that of a comparable general Italian population. Recoarctation occurred in only $8 \%$ of patients who had end to end anastomosis, whereas it occurred in $35 \%$ of those who had other types of operation. Two thirds of the patients were hypertensive at the last visit. The actuarial curve shows that blood pressure was normal in most patients 5-10 years after operation, but 30 years after coarctation repair only $32 \%$ of patients are expected to be normotensive.

Thus early repair of aortic coarctation appears to improve long term survival. Intervention in older patients and when blood pressure is high seem to be the most important predictors of late hypertension.

Forty years after the first successful operation for the relief of aortic coarctation ${ }^{1}$ there is still controversy about the optimal age and the most suitable technique for the repair of this anomaly. ${ }^{2-4}$ Long term morbidity and mortality remain high, with complications and deaths being mainly the result of associated cardiovascular lesions, infective endocarditis, and residual or recurrent coarctation and hypertension. ${ }^{5-7}$

We have analysed the long term results of a large group of patients operated on in our institution 15 to 30 years ago.

\section{Patients and methods}

PATIENTS

Two hundred and forty four patients (163 male and 81 female) were operated upon from 1954 to 1969 in

Requests for reprints to Dr P Presbitero, Istituto di Medicina e Chirurgia Cardiovascolare, Cardiologia $I^{\circ}$, Ospedale Molinette, Corso Bramante, 10100 Turin, Italy.

Accepted for publication 15 September 1986 our department. In all patients the diagnosis had been confirmed by angiography. Two hundred and twenty six patients left the hospital and were followed for 15-30 years (mean 20 years). Resection with end to end anastomosis had been performed in 170 patients; Clagett's operation ${ }^{8}$ (end to end anastomosis of the left subclavian artery to the descending aorta) in 25; a prosthetic tube graft had been inserted in 24; and three required a patch repair. Four patients had an operation of another type.

Patients were aged 4-48 years (mean 20) at operation. Their age at last examination ranged from 19 to 65 years (mean 40 ).

Twenty six patients died and 17 were lost to follow up. Forty patients could be contacted only by telephone. The remaining 143 were assessed in our department.

\section{METHODS}

Blood pressure in the arm was measured by a standard sphygmomanometer with a cuff that was $14 \mathrm{~cm}$ wide and $48 \mathrm{~cm}$ long. Systolic pressure in the legs was measured in either the popliteal artery by means 
of a cuff that covered at least two thirds of the thigh or in the posterior tibial artery by a cuff that covered at least two thirds of the calf.

An electrocardiogram and chest $x$ ray were obtained in all 143 patients who were reassessed in our department. Twenty patients had left heart catheterisation and angiography because recoarctation or additional cardiovascular anomalies were suspected. Patients aged $>30$ years were regarded as hypertensive when their systolic blood pressure was $>160 \mathrm{~mm} \mathrm{Hg}$ or the diastolic pressure was $>95$ $\mathrm{mm} \mathrm{Hg}$ or both. In those aged between 19 and 30 years hypertension was defined as a systolic pressure of $>150 \mathrm{~mm} \mathrm{Hg}$ or a diastolic pressure of $>90$ $\mathrm{mm} \mathrm{Hg}$ or both. ${ }^{910}$ All patients on antihypertensive treatment were regarded as having hypertension.

Recoarctation was diagnosed when the pressure gradient between arms and legs was $>20 \mathrm{~mm} \mathrm{Hg}$ at rest or $>30 \mathrm{~mm} \mathrm{Hg}$ after exercise. ${ }^{1112}$ Fifteen of the 17 considered to have recoarctation consented to cardiac catheterisation; this confirmed the clinical diagnosis in all except two of the patients who had a gradient of $<20 \mathrm{~mm} \mathrm{Hg}$.

Standard actuarial methods were used to calculate cumulative incidence rates. ${ }^{13}$ Cumulative actuarial curves of survival were constructed for our patients and these were compared with the actuarial survival curves of the Italian population in the years 1967-69. We also compared our results with the survival curves reported by Campbell in patients with coarctation who were not treated by operation. ${ }^{14}$

The actuarial curves of postoperative blood pressure were constructed from the patients' personal medical records and history. Those with recoarctation were excluded. The prevalence of hypertension in our population was compared with that in the Italian population. ${ }^{15}$ Hypertension is more common in males than in females and also increases with age. Because the distribution of age and sex in our patients was different from that in the Italian population we have adjusted the crude (observed) hypertension rates of our patients according to the age and sex specific rates of the general Italian population, using the indirect standardisation of rate, ${ }^{16}$ to give the expected rates.

We used the $\chi^{2}$ test to compare the observed and expected data. Between group comparisons were made by the two tailed test of proportion. Differences of $p<0.05$ were regarded as significant. Data are presented as mean (SEM). Qualitative variables were compared by means of a multifactorial log linear model. ${ }^{17}$

\section{Results}

LATE MORTALITY

Twenty six patients died 1-30 years (median 12 years) after the operation at a mean age of 39 years (range 15-53 years). Three patients died of causes related to the surgical repair. Two had had a Clagett's anastomosis; one of them died 16 years after surgery of a ruptured aneurysm of the thoracic aorta and the other died of bleeding at the site of anastomosis after a reoperation 10 years after the first operation. The third patient, in whom a long coarctation had been replaced by a prosthetic tube graft, died of endocarditis a year later.

Seven patients died of coronary heart disease at a mean age of 38 years; four died in cardiac failure because of associated cardiac lesions. Two patients died suddenly. Three patients, two of them with recoarctation, died of a cerebrovascular accident. Two patients died in motoring accidents and in five cases the cause of death is unknown. The mean age at operation was $25(1.45)$ years in the patients who died and $19(0.67)$ those who survived $(p<0.02)$.

The type of surgical repair seemed to affect late survival. Only $6.3 \%$ of the patients who had had end to end anastomosis died, whereas $23 \%$ of those who had had other kinds of operation died $(p<0.01)$. In patients aged $>20$ years at operation, $10 \%$ of those who had an end to end anastomosis and $36 \%$ of those with other kinds of operation died $(p<0.05)$; thus the type of operation remains an important additional independent risk factor even in patients who were older at operation.

The distribution of age adjusted mortality rate (fig 1) shows that most late deaths after the intervention occurred between the fourth and the fifth decade; in Campbell's study mortality rates reached a peak two decades earlier in patients with coarctation that was not treated by surgical repair. ${ }^{14}$

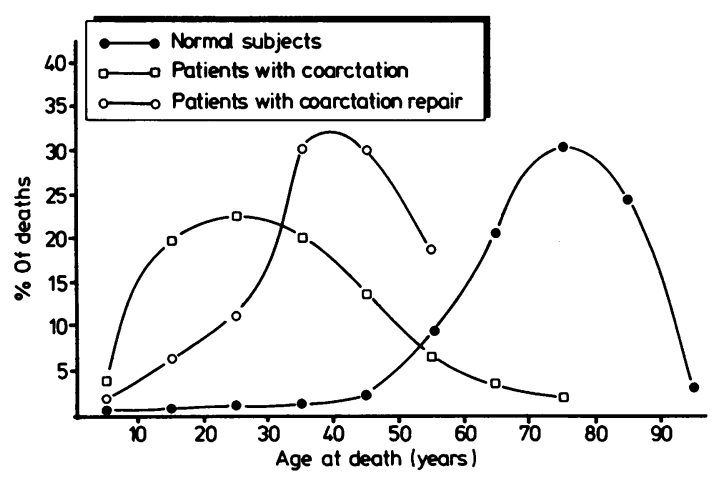

Fig 1 Distribution of death by age of subjects with coarctation, of subjects with coarctation repair, and of the general population. The curves on the left and right are taken from Campbell. ${ }^{14}$ The middle curve shows the distribution of death in our patients with coarctation repair. These curves have been adjusted for age. 
SURVIVAL

Thirty years after operation the actuarial survival is $78(6) \%$ (fig 2). In patients aged 4-20 years at operation survival is $97 \%, 97 \%, 92 \%$ at 10,20 , and 30 years after operation. For those operated on after the age of 20 the corresponding rates are $93 \%, 85 \%$, and $68 \%$. The difference between the two curves becomes statistically significant from the fifteenth year of follow up onwards.

To evaluate the influence of age on mortality, we have compared the survival at 15 and 30 years of our operated patients with the survival curves of the general Italian population (fig 3 ). The patients were divided into four groups according to their age at operation: group 1, 4-14 years; group 2, 15-24 years; group 3, 25-34 years; group 4, 35-48 years. Up to 15 years after the operation survival was not significantly different in the four groups of operated patients and in the general population. At 30 years, survival was significantly worse in groups 2 $(p<0.003)$ and $3(p<0.00047)$ than the general population. None of the 17 patients in the oldest age group (group 4) had died within 30 years of operation. This group is not included in fig 3, however, because the number of patients was too small for valid statistical analysis.

Patients who had an operation for coarctation lived longer than those who did not, but they did not have the life expectancy of the general population (fig 4). The percentage of survivors at the end of each decade up to the age of 30 equals that of the general population. But survival later decreases; however, the pattern of the curve remains similar to that of the general population.

Most survivors of surgical repair live normal lives:

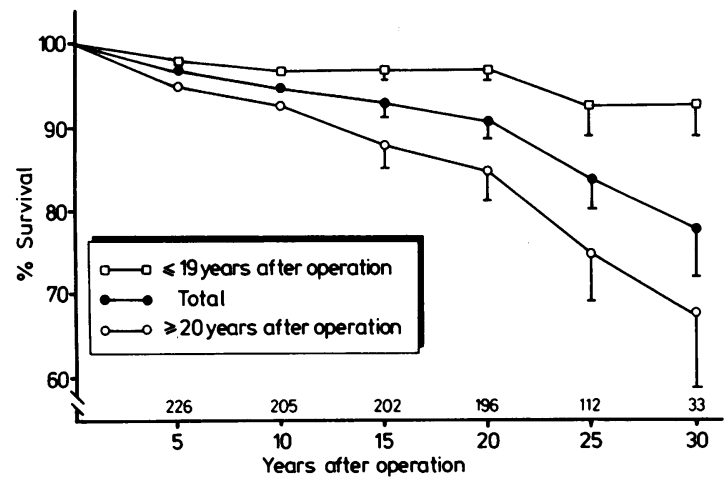

Fig 2 Actuarial curves of patients excluding deaths in hospital. The middle curve shows the actuarial survival of all the patients. The upper and lower curves relate the chance of long term survival to age at operation. Absolute numbers are given on the horizontal axis.

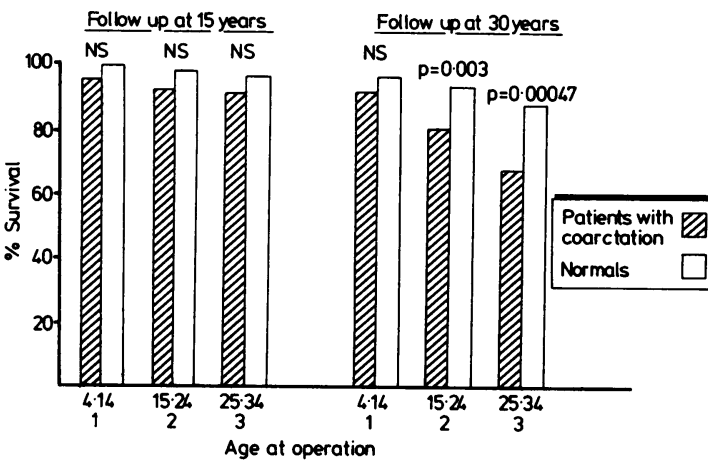

Fig 3 Survival of patients at 15 and 30 years follow up divided into three groups (group 1, 65 patients; group 2, 67 patients; group 3, 60 patients) according to age at operation. The survival was compared with that of the general Italian population (ISTAT data for 1967-69) ${ }^{18}$ of the same age group and for the same period of follow up.

$81 \%$ are in New York Heart Association functional class I, $15 \%$ in class $I I$, and $4 \%$ in class III.

\section{ELECTROCARDIOGRAM}

The electrocardiogram was normal in $48 \%$ of the patients (68/143). Twenty one had signs of left ventricular hypertrophy; 10 of them had systemic hypertension, two had recoarctation, four had aortic valve disease, and five were normotensive without any associated anomaly. Fifteen patients had complete left bundle branch block and 15 had complete right bundle branch block. Two patients had a pacemaker because of complete heart block; both of them

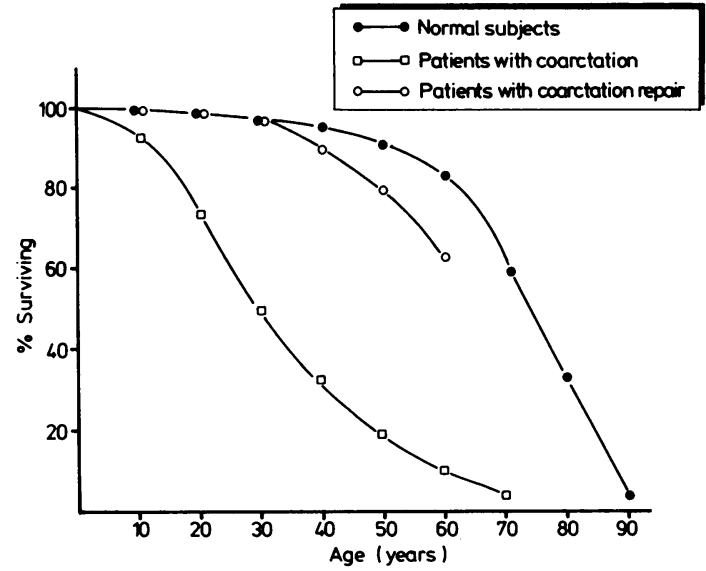

Fig 4 Percentage of the subjects still alive at the end of each decade. The curve on the right (normal subjects) and the curve on the left (subjects with coarctation) are taken from Campbell ${ }^{14}$ and the curve in the middle is drawn from our data. 
had severe aortic valve stenosis. Two patients had atrial fibrillation; one had ventricular septal defect and the other had mild aortic stenosis. One patient had a Wolff-Parkinson-White pattern; in 19 cases only non-specific ST-T changes were recorded.

\section{ASSOCIATED ANOMALIES}

The presence of associated abnormalities was diagnosed mostly on clinical and echocardiographic grounds. In a few patients the diagnosis was confirmed by cardiac catheterisation. Thirty eight $(44 \%)$ of the 86 patients in whom either a cross sectional echocardiogram or an angiogram was obtained had evidence of a bicuspid aortic valve. Fourteen $(9.8 \%)$ of 143 had moderate to severe aortic valve stenosis or insufficiency or both. Three patients had an aortic valve replacement 16-20 years after coarctation repair and four patients are awaiting operation. The seven remaining patients are being followed up.

There was clinical and echocardiographic evidence of mitral regurgitation in four; in two of them it was due to a mitral valve prolapse. A small ventricular septal defect was detected in two patients and another patient (aged 56) has a ventricular septal defect with a 2.8:1 shunt and is awaiting operation. In all cases the defects were perimembranous.

Two of three patients with discrete subaortic stenosis were operated on seven and nine years after coarctectomy. One had an additional supravalvar aortic stenosis relieved at operation. In the second patient a bicuspid aortic valve and an aneurysm of the perimembranous septum were also found at operation. In the third patient, who was not operated on, the stenosis was discovered by cross sectional echocardiogram 17 years after the operation.

In three patients dilated cardiomyopathy was discovered by cross sectional echocardiography 27-30 years after the surgical repair of the coarctation. In all angiography showed diffuse ventricular hypokinesia without coronary lesions. One of these patients had a $30 \mathrm{~mm} \mathrm{Hg}$ pressure gradient across the aortic valve and severe mitral regurgitation due to dilatation of the annulus. Another had a 20 $\mathrm{mm} \mathrm{Hg}$ pressure gradient across the coarctation but no aortic valve stenosis or regurgitation, and the third one had no residual gradient.

Three patients had clinical evidence of coronary artery disease.

\section{RECOARCTATION}

Fifteen of the 143 reassessed survivors had recoarctation; the gradient varied from 20 to 100 $\mathrm{mm} \mathrm{Hg}$. One patient had successful reoperation; six of the 26 patients who died during follow up had recurrent coarctation.
Eight per cent of the patients with end to end anastomosis and $35 \%$ of those in whom the intervention was of another type had a recurrent coarctation. This difference is statistically significant $(p<0.01)$, whereas there is no difference between patients operated on at a younger or older age.

\section{HYPERTENSION}

Forty six of 128 patients had systemic hypertension without recoarctation. Figure 5 shows the actuarial curve for the presence of hypertension. Blood pressure was normal in most patients seen 10 years after operation, but later hypertension gradually became more frequent. Thirty years after coarctation repair only $32 \%$ of the patients are expected to be normotensive. Late hypertension was less common in patients operated on at younger ages ( $<20$ years), but this difference was statistically significant only in the period between 15 and 25 years of follow up. The number of patients with a longer follow up was, however, small.

Because the incidence of hypertension in our population seemed to increase with the length of the follow up and therefore with the age of the patients, as it does in the general population, we compared the prevalence of hypertension in our population with that of the general Italian population for each decade. ${ }^{9}$ In the patients who had surgical repair hypertension was more than 1.34 times more common than would be expected in the general Italian population $\left(\chi^{2}=4.5, \mathrm{p}<0.05\right)$. We also found that the standardised ratio for hypertension was 1.15 in the patients operated on before the age of 35 years ( $\chi^{2}$ not significant) and 1.37 in the patients operated on after that age $\left(\chi^{2}=4.60, p<0.05\right)$. This means that the patients operated on at an older age are more

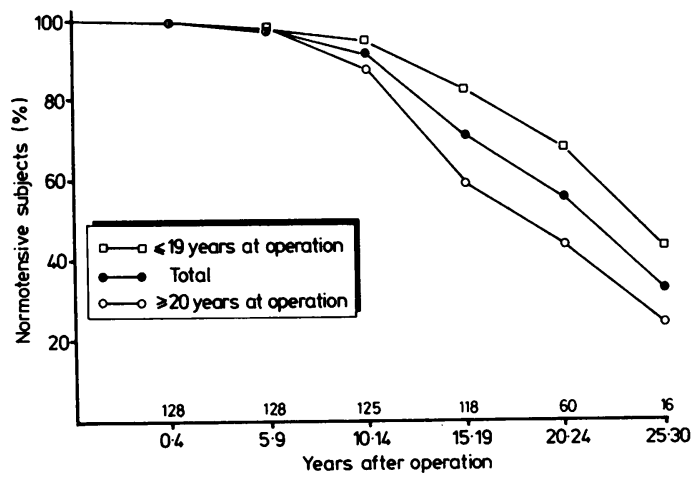

Fig 5 Actuarial curves for continuing normotension in patients (absolute numbers are given on horizontal axis). The middle curve shows the actuarial percentage of normotensive patients among all the patients. The upper and lower curves relate the chance of long term normotension to the age at operation. 
likely to become hypertensive than the general Italian population. Hence the difference between the two curves in fig $\mathbf{5}$ is due not only to the fact that one group of patients is older, but also to the fact that surgical repair was performed.

Patients with higher preoperative blood pressure had a tendency to have late hypertension. To assess this effect we examined preoperative and present blood pressure levels in the 97 patients in whom both were available after excluding patients with recoarctation. Hypertension was less common $(25 \%)$ at the last postoperative examination in patients with a preoperative blood pressure of $\leqslant 200$ $\mathrm{mm} \mathrm{Hg}$ than it was in those in whom the preoperative blood pressure was $>200 \mathrm{~mm} \mathrm{Hg}$ before operation $(60 \%)(\mathrm{p}<0.01)$.

Multifactorial analysis (log linear model) shows that in patients with late postoperative hypertension there is a positive correlation with high preoperative blood pressure and with an older age at operation. This means that a patient who is $>20$ at operation with a very high blood pressure will have little chance of becoming and remaining normotensive after the operation.

\section{Discussion}

DOES COARCTATION REPAIR IMPROVE LIFE EXPECTANCY?

The goals of operation in aortic coarctation are prolongation of life and relief of symptoms, including normalisation of blood pressure. Our data confirm that life expectancy was significantly higher in our patients than in those who were not operated upon; however, it remains lower than in the general Italian population (fig 4). The shorter life expectancy after an apparently successful repair in our series was mostly the result of cardiovascular causes. Premature coronary artery disease, congestive heart failure, and cerebrovascular accidents, which were probably related to congenital aneurysms of brain arteries, were the commonest causes of death. Except for ischaemic heart disease, the causes of death in our patients resembled those reported by Campbell in a series of patients with coarctation that was not treated by surgical repair. ${ }^{14}$

\section{IS AGE AT THE TIME OF OPERATION}

IMPORTANT?

Age at operation does not seem to influence survival during the first 15 years of follow up (fig 2). Afterwards life expectancy is significantly lower than in the general population in those in whom the operation was performed after the age of 14. Furthermore, all but one of our patients who died because of coronary artery disease were older than 20 at the time of coarctation repair.

No patients operated upon after the age of 35 died. Patients who survived to be operated on after 35 may have had the mildest form of the disease. The small number of such patients precludes any firm conclusion, however.

The three main problems encountered in patients operated on for coarctation were associated anomalies, recoarctation, and late hypertension.

\section{ASSOCIATED ANOMALIES}

A bicuspid aortic valve is common in patients with aortic coarctation. Careful follow up is necessary in these cases because clinically important aortic stenosis and insufficiency may develop. An important aortic valve lesion, which may have been related to the presence of bicuspid aortic valve, was found in about $10 \%$ of the patients. Some required operation.

Serious coronary heart disease seems to be common in our patients despite their youth. It was the $\bar{z}$ commonest cause of late death. We cannot say whether coronary artery disease in such patients $\vec{\varphi}$ develops because of residual hypertension or $\stackrel{\infty}{\forall}$ because of associated anomalies.

Ventricular septal defect, mitral insufficiency, and dilated cardiomyopathies are rare. In the individual cases, however, these conditions can influence late ou+come.

\section{RECOARCTATION}

As reported elsewhere ${ }^{1119}$ recoarctation was not a major problem in patients who were $>4$ years old if they had an end to end anastomosis $(8 \%)$. Recurrences were rather common (35\%), however, in those in whom different operative techniques (Clagett, prosthetic tube) were used. Such techniques are now seldom used.

\section{LATE HYPERTENSION}

About $30 \%$ of our patients had hypertension after coarctation repair. This figure is similar to that reported by others. ${ }^{231120}$ Hypertension is often associated with the development of recoarctation and its cause remains unknown. It is more frequent $\tilde{N}$ in patients operated upon after the age of 20 and it $\underset{\omega}{N}$ may appear 10-15 years after an apparently success- $O$ ful repair.

This is not solely due to the normal aging process, since the percentage of cases with arterial hyper-? tension in patients with a successfully operated coarctation is higher than in the general population of the same age.

From our data it also appears that a high preoperative blood pressure predisposes the patient to the development of hypertension. 


\section{LIMITATION OF THE STUDY}

Our patients were operated on between 1954 and 1969 and preoperative investigations were, therefore, limited; no intracardiac pressure measurements, no coronary angiography, no echocardiography, and only few aortograms were performed. The diagnosis of coarctation was always confirmed at surgery, however.

Not all patients had an annual examination; however, at least one intermediate blood pressure measurement was available and the time that hypertension reappeared could be determined with confidence. Furthermore, our own evaluation was mainly conducted on clinical grounds; invasive investigations were confined to patients in whom we suspected complications or additional anomalies or both. Not all patients had an echocardiographic examination. Our study group included 25 patients who had operations (mainly Clagett's procedure) that have subsequently been abandoned.

\section{Conclusions}

A successful coarctectomy prolongs life. The benefits of the operation are, however, limited by age and severe hypertension at operation, and by associated anomalies and premature coronary artery disease. Recoarctation is uncommon but the incidence of unexplained recurrent hypertension is high.

We thank Professor A Dato who operated on most of the patients we reviewed.

\section{References}

1 Crafoord C, Nylan G. Congenital coarctation of the aorta and its surgical treatment. $J$ Thorac Surg 1945;14:347-61.

2 Liberthson R, Pennington D, Jacobs $M$, et al. Coarctation of the aorta: review of 234 patients and clarification of management problems. Am J Cardiol 1979;43:835-40.

3 Maron BJ, Humphries O, Rove RD, et al. Prognosis of surgically corrected coarctation of the aorta. A 20 years postoperative appraisal. Circulation 1973;47: 119-26.

4 Menasche $\mathrm{Ph}$, Blondeau $\mathrm{Ph}$, D'Allaines $\mathrm{C}$, et al. Résultats lointains de la correction chirurgicale de la coarctation de l'aorte. Étude de 90 malades opérés depuis il à 15 ans. Arch Mal Coeur 1978;1:181-90.

5 Simon AB, Zloto AE, et al. Coarctation of the aorta. Longitudinal assessment of operated patients. Circulation 1974;50:456-64.

6 Morino F, Santarelli P, Lino R, et al. Coartazione dell'aorta. Risultati a distanza del trattamento chirurgico a proposito di 113 casi seguiti fino a 10-12 anni dall'intervento. Minerva Cardioangiol 1976;24: 799-815.

7 Pollack P, Freed MD, Castaneda AR, et al. Reoperation for isthmic coarctation of the aorta: follow-up of 26 patients. Am J Cardiol 1983; 51:1690-4.

8 Clagett OT. Coarctation of the aorta; surgical aspect. Proc Staff Meet Mayo Clin 1948;23:359-63.

9 Ambrosio GB, Bulgaro L, Gabaldo S, et al. Blood pressure and its spontaneous variations in the northern Italian population. Clin Sci Mol Med 1976; 51:669-710.

10 Kaplan N. Systemic hypertension mechanism and diagnosis. In: Braunwald $\mathrm{E}$, ed. Heart disease. A text book of cardiovascular medicine. Philadelphia: WB Saunders, 1980:852-921.

11 Clarkson PM, Nicholson MR, Barrat-Boyes BG, et al. Results after repair of coarctation of the aorta beyond infancy: a 10 to 28 years follow-up with particular reference to late systemic hypertension. Am J Cardiol 1983;51:1481-8.

12 Connor PM, Baker WP. A comparison of coarctation resection and patch angioplasty using post exercise blood pressure measurement. Circulation 1981; 64:567-72.

13 Colton T. Statistics in medicine. Boston: Little Brown, 1975.

14 Campbell M. Natural history of coarctation of the aorta. Br Heart $J$ 1970;32:633-40.

15 Ambrosio GB, Zambon S, Varnizzo D, et al. La prevalenza di ipertensione arteriosa nella comunità. L'esperienza del Veneto. G Ital Cardiol 1980; 10:1280-7.

16 Rose G, Barker DJP. Comparing rates. $\mathrm{Br}$ Med J 1978;ii:1282-3.

17 Brown M. Multiway frequency tables. The log-linear model. Los Angeles: University of California Press, 1981.

18 ISTAT. La popolazione italiana. Rome: Poligrafico dello Stato, 1982.

19 Naton MA, Olley PM. Residual hypertension after coarctectomy in children. Am J Cardiol 1976; 37:769-72.

20 Björk VO, Begdahl L, Jonasson R, et al. Coarctation of the aorta. The world's longest follow-up. Adv Cardiol 1978;22:205-15. 